\title{
The Evaluative Function as Part of the Hidden Pragmatic Meaning of Certain Expressions in English and Spanish
}

\author{
Laura Alba-Juez \\ National Distance Education University (Madrid) \\ AND \\ Elena Martínez-Caro \\ Universidad Complutense de Madrid
}

W

e present here an analysis of the pragmatic meaning that is associated with the use of the English expressions no wonder and I wouldn't be surprised (iflto)... and their Spanish equivalents no me extraña (que) and no me sorprendería (que)/no me extrañaría (que).... Previous studies, such as those by Sinclair, Louw, and Channel, have pointed out that a given word or expression can take on an association with the positive or the negative, and that this association can be exploited by the users of the language in question to express evaluative meaning covertly, a phenomenon that has been given the name of "semantic prosody" by some authors. Following these scholars, we analyze the evaluative function of these five expressions in English and Spanish. Even when from the strictly semantic point of view they do not have an inherent negative meaning, they are mostly associated with such kind of meaning and they occur most frequently in the context of other words or phrases that are predominantly negative in their evaluative orientation. Thus, the phenomenon is additionally examined as a case of "evoked" rather than of “inscribed appraisal," borrowing Martin's terms ("Appraisal Systems”). We also examine, somewhat briefly, the five expressions in the light of some prominent discourse/pragmatic theories, identifying their role as "attitudinal stance markers," in the sense given to the term by Conrad and Biber, and as carriers of important evaluative cohesive devices. In addition, some considerations are made on the fact that the negative evaluation associated with these expressions produces a message of, to use Fetzer's terms, "non-alignment," and consequently the stance taken aids in the construction of the speaker's discursive identity.

The analysis is derived from concordanced examples taken from the COCA (Corpus of Contemporary American English), the BNC (British National Corpus), the Davies' Corpus del Español, the CREA (Corpus del Español Actual) and some examples obtained by means of the Google search of the expressions. Our intention 
was to address objective observable data, in an attempt to demonstrate, among other things, that a corpus-based analysis can reveal aspects of the evaluative function that native speaker's intuitions most often fail to pick up. In agreement with Channel, we believe that the analysis of the evaluative function of language "can be removed from the chancy and unreliable business of linguistic intuitions and be based in systematic observation of naturally occurring data" (39). In effect, study of no wonderlI wouldn't be surprised (iflto)... and no me extrañal no me sorprendería quelno me extrañaría que (hereinafter no wonder, etc.) within a corpus of natural data, together with its consequent qualitative and quantitative (statistical) results, has thrown considerable light on their pragmatic "hidden" but very real meanings, which should be taken into account in any lexical description of the expressions. The quantitative analysis of the English corpora data ${ }^{2}$ has also helped us to reach some conclusions about the varying genre distribution of the evaluative polarity of the English expressions, as well as general conclusions regarding the relationship between the variable of genre and the evaluative function of language.

No wonder, etc. are linguistic variables that normally modify one or more subordinate clauses within their scope. Our primary hypothesis is that these expressions are very frequently associated with a negative attitude or evaluation, and therefore the clauses found in their scope display a predominantly negative meaning. In most cases, this negative polarity not only affects the clause(s) directly modified by the variable but also the surrounding words or expressions, which are loaded with overt negative semantic meanings. But let us clarify what we mean by semantic and pragmatic meaning: whereas both pragmatic and semantic studies are concerned with meaning, ${ }^{3}$ there is general consensus among linguists nowadays in considering that semantic meaning has to do with the truth conditions of sentences and pragmatic meaning with the use of utterances in a given context. ${ }^{4}$ As Channel explains, the encoding of attitude or evaluation can be either semantic or pragmatic (38). When it is semantic, the evaluative meaning is expressed in an overt way; when it is pragmatic, the evaluative attitude is presented covertly. Example 1 illustrates overt evaluative meaning:

\section{(1) Peter is a crook.}

Here the negative evaluation is inherent to the word "crook," i.e. it is inscribed in the semantic features of the word, and thus the speaker is overtly committed to the fact that his evaluation about Peter is negative: he thinks he is a crook and so he clearly and directly expresses his attitude. Graphically, and in Martin's terms, this example could be labelled as an instance of "inscribed appraisal" (142).

In contrast, example 2 illustrates basically the same evaluative meaning (negative), but in a covert way: 


\section{(2) No wonder Peter joined that club!}

Here the expression "No wonder" is modifying the subordinate clause "Peter joined that club," which, in the proper context (e.g. when both speaker and hearer know that the club that Peter joined has a bad reputation) will surely mean that the speaker is negatively evaluating Peter, by implying that he is a crook and for that reason he joined such a disreputable club. Martin labels this kind of evaluation as "evoked appraisal" (142). Table 1 summarizes the difference between these two main kinds of meaning:

Table 1

\begin{tabular}{|c|c|}
\hline SEMANTIC/ OVERT MEANING & $\begin{array}{c}\text { PRAGMATIC/ COVERT } \\
\text { MEANING }\end{array}$ \\
\hline Peter is a crook & No wonder Peter joined that club \\
\hline Peter is a crook & Peter is a crook (or so I think) \\
\hline $\begin{array}{l}\text { The encoding of the negative attitude } \\
\text { is semantic }\end{array}$ & $\begin{array}{l}\text { The encoding of the negative attitude } \\
\text { is pragmatic, and present in addition } \\
\text { to the semantic meaning of the words } \\
\text { or expressions used. It constitutes } \\
\text { part of the common knowledge the } \\
\text { interlocutors share. }\end{array}$ \\
\hline Inscribed appraisal & Evoked appraisal \\
\hline
\end{tabular}

We are conscious of the fact that these expressions can also be used in a context where a positive evaluation is made. In another proper context, "No wonder Peter joined the club" could be interpreted as a compliment to Peter if, for instance, the interlocutors have the common knowledge that Peter is a very prominent and prestigious scientist and if the club were an association of all kinds of outstanding academics. In effect, we have also found instances in the corpora where all the expressions under scrutiny are loaded with positive, or even neutral, evaluative meaning. And this is precisely why we can speak of pragmatic meaning: if the negative evaluation were inscribed in the semantic features of the expressions studied, we would not be making any finding worth investigating. The interesting aspect is that, even when these expressions can be used to present both negative and positive evaluative meaning, there seems to be a tendency for them to be preferably associated with negative evaluation by the speakers of the two languages in question. 
The study of indirect, pragmatic evaluative meaning could be approached from different perspectives. Appraisal Theory, as conceived by Martin, or Martin and White, is one of them. Looking at our corpus examples from this approach, we have found that the evaluation implied in the use of these expressions may fall within any of its three sub-systems. As we know, all three have both a positive and a negative dimension. The frequency of occurrence of the latter has proved to be higher for the expressions studied herein, as the examples in 3 illustrate through the negatively charged language found in their linguistic context.

\section{(3) Affect (expression of displeasure):}

No wonder voters are angry! (CNN.com)

Judgement (negative criticism):

Bueno, entonces no me extraña que les califique de gentes impresentables pertenecientes a ese gallinero internacional que llamáis la 'jet-set'. (CREA, Prensa 1977)

Appreciation (lack of balance and unnecessary complexity):

No wonder we are so confused! (COCA Corpus, San Francisco News 1990)

Another view to which the evaluative function is inevitably tied up is that of Politeness Theory, within which, considering Brown and Levinson's taxonomy, the use of no wonder, etc. can be classified as an off record (face-saving) strategy utilized to express certain judgments whose implied negative evaluation has to be worked out by the hearer by means of implicature. Whether this indirectness is really face-saving-i.e., whether it is always interpreted as less offensive than a direct criticism by the "victim" of the evaluation—can be argued, for it depends on the interlocutors, the situation and the culture in question.

Another option could be to look at this phenomenon through the prism of pragmatic markers theory: the four expressions under study play a prominent role as "attitudinal stance markers," in the sense given to the term by Conrad and Biber, indicating feelings or judgments about what is said or written. An interesting feature is that they are often used as stance markers in conjunction with verbal irony, a phenomenon that is also associated with the expression of attitudes and with predominantly negative evaluations and judgments, as has been shown by, for instance, Alba Juez, Attardo, Barbe, Brown and Levinson, Kaul de Marlangeon, and Torres Sánchez. Example 4 shows this combination, where the subordinate clause of no wonder contains an apparently positive word like "fairness" used in an ironical way, and where the linguistic context (containing words with negative semantic meaning, such as "killed" or "deficit") also helps in the interpretation that the writer of the article is critical or at least rather skeptical about some Democratic procedures. 
(4)

The swing voters who have drifted into GOP ranks over the last decade may now be moving back to the Democratic camp. No wonder the Democrats intend to exploit the "fairness" issue again in the next Congress by bringing back their plan to slap a surcharge on millionaires, which was killed in the final stages of the deficit package.

(COCA Corpus, USNWR 1990,)

These expressions could also be examined in the light of discourse identity studies, considering the fact that the negative evaluation associated to them produces, as Fetzer would call it, a message of "non-alignment," and consequently contributes to the building of a determinate discursive identity. Example 5 is an instance of a newspaper article where the columnist clearly aligns herself against former President Bush: i.e., she identifies herself against Bush's policy of not reading newspapers and relying only on what his aides tell him. This evaluation is thematically placed on the headline, presenting her attitude and identity from the very first line of her article.

No wonder Bush doesn't connect with the rest of the country-15 Oct. 2003 ... If the president doesn't read newspapers but relies only on his aides, then I wonder if they told him about Kimberly Requell Mari Brice, the Landover, Md., 5-year-old first grader who was fatally shot by her 4-year old brother.... (www.seattlepi.com/opinion/143851_thomas15.html)

Without disregarding the fact that all these approaches can prove to be very useful for the interpretation of the phenomenon studied, we have verified that simple, straightforward corpus analysis (not necessarily committed to any of the abovementioned approaches in particular) suffices to test our hypothesis. As can be observed in examples 1 through 5, the concordances of the expressions in both the English and the Spanish corpora appear very frequently in the vicinity of other words and expressions whose semantic meaning has clear negative features, and which consequently give no wonder, etc. an obscure, negative tint. Examine, for instance, the extended context of one of the English concordances in example 6, where the expression no wonder is surrounded by words such as "terrifying," "murdered," "burglarized," etc.

(6)

The numbers are truly terrifying. Last year alone, for every 100,000 people in the city, 34 were murdered, 116 raped, nearly 4,000 were burglarized. No wonder so many are so afraid to live in Dallas. That's right, Dallas. Last year, it was the worst city for major crime in America. New York, Crime City U.S.A., was number 13. (COCA Corpus, "The Rotten Apple," ABC Primetime 1990) 
The use of concordances and electronic corpora has proved to be crucial, thus, for the finding of hidden evaluative meaning. Normal native speakers of English or Spanish would not be particularly conscious of the fact that much of the language they use in everyday life encodes this kind of meaning. The corpus query of specific linguistic expressions, then, can prove useful for making us aware of this fact as, once more, the concordances in 7 for English and in 8 for Spanish seem to reveal for no wonder and no me extraña, respectively.

(7)

"I don't like all this mystical nonsense Julian feeds the child. No wonder she's tied up in knots. Amber for Amber / What does that mean?" (1990FICBkGen: SingingStones)

"there was something indescribably alien about the way reptiles hunted their prey. No wonder men hated reptiles. The stillness, the coldness, the pace was all wrong." (1990FIBkSF: JurassicPark)

"Kata? Are you crazy? Hoy, Lil, no wonder you've taken up with psychopathic murderers." (1990FICBkSF: AlchymistsJournal)

"that this tunnel is almost one hundred and seventy-five years old? It's no wonder they had trouble. They doubtless did not maintain it properly." (1990FICBkSF: AlchymistsJournal)

"Nathan, I would like to think it is still possible. No wonder people are talking about him. They think he's either mad or possessed." (1990BkGen: PillarLight)

(8)

"que planear, pero como si notara yo misma que pesaba mucho—No me extraña. Idiota. Ha sido sin motivo de." (OREspaña Oral CCON032A)

"casos, c. Venían asustados. ¡Que sí! ¡Que no me extraña! Yo la práctica la salvo. La teoría....” (OREspaña Oral CCON034A)

"habido problemas porque querían venir todos, pero cuando hemos empezado a hablar No me extraña. todos quieren, quiénes eran esos todos.... Bueno, querían venir todos los novilleros." (OREspaña Oral CENT007A)

"miedo de que volviera otra vez. Es que teniendo una madre bruja no me extraña. Claro, claro y soñaba con ella, ¿eh? y yo no." (OREspaña Oral CENT012B)

If a word or expression is very frequently surrounded by other words or expressions containing negative semantic meaning, it is very likely that the former ends up being associated with negative evaluations, even when it does not have any negative semantic feature per se, as the result of the corpus query seems to show for no wonder, etc. This observable fact supports our hypothesis, considering, in addition, that the subsequent quantitative analysis has shown that negative polarity has a considerably higher rate of occurrence than positive or neutral polarity. 
In syntactic terms, no wonder is best seen as part of a subject extraposition construction. In this construction, no wonder is the subject complement of the main attributive verb (usually the form of the copula "is"), preceded by an anticipatory dummy "it" as syntactic subject, the clausal (notional) subject, a "that"-clause, appearing as an extraposed element in the sentence final position. Notice that the non-extraposed alternative is generally not possible in English. The pattern is illustrated in the following examples.

It was no wonder that the position was described in the House of Commons in 1871.

(BNC, ED5 W_ac_polit_law_edu)

And yet it is no wonder that Lear, with all his knights, is becoming a nuisance. (BNC, HD8 $\underline{\mathrm{W}}$ essay school)

Extrapositions are often found in English to express evaluation, a judgement on the part of the speaker or writer on what is expressed in his/her utterance. Hunston and Thompson, for instance, give the following examples of extraposition for expressing an opinion of goodness or desirability and of certainty (3):

It is gratifying to receive recognition from our travel industry partners.

It is fairly certain that you would take those odds seriously.

The expression no wonder is also found in forms differing from the extraposition pattern in full, mentioned above. The construction, for instance, may be introduced by a contraction of the dummy "it" and the copula ("it's'), or it may omit different elements, such as the conjunction "that" or, maximally, the dummy "it" + copula and the conjunction "that" introducing the subordinate clause, in what is a common occurrence of the expression. See 12, for instance.

No wonder he's out of a job.

(BNC, J1J W_email)

In cases like this, no wonder seems to be functioning as a grammaticalized lexical unit, having lost its main semantic meaning and with the general function of introducing the clausal subject that follows. Biber et al. refer to the concept of "utterance launcher," as "lexical bundles ... presenting a personal stance relative to the information in the following complement clause." Although they mention 
here sequences such as "I think," "I know," "I mean," and others, we find it obvious that no wonder, in the cases mentioned where there is omission of the dummy subject and the copula, can be also characterized in the same way.

Showing the same pattern as no wonder, the expressions in Spanish no me extraña(ria)... and no me sorprendería... are also followed by extraposed clausal subjects. In Spanish these clausal subjects are normally introduced by the conjunction que.

(13)

Yo no sé lo que pensará Felipe González, pero no me extrañaría que estuviera pensando hacerlo; pero....

(CREA, Prensa, El País, 01/08/1987)

In the case of I wouldn't be surprised, this sequence is followed by a complement clause dependent on surprised, as an "if"-subordinate clause or "to"-infinitive clause, as in the following:

I said to Sally I said I wouldn't be surprised if they two get married.

(BNC, $\mathrm{KBE}, \mathrm{S} \_$conv)

And I wouldn't be surprised to see both candidates emerge with a female vice president. (COCA Corpus, 2008, SPOK, Fox_Gibson)

Both no wonder and I wouldn't be surprised may also occur alone, forming a single tone unit and information unit:

Baffled? Confused? Overwhelmed? No wonder. It's an advertising war out there. (COCA Corpus, 1990, SPOK, ABC_Primetime)

I wonder. Has he run out of cash? Well, I wouldn't be surprised. Why would he need to do it in the dark? Well if for instance....

(BNC, KCO, S_conv)

Syntactically, they can be seen as incomplete or reduced clauses. Especially in the case of no wonder, they can be classified as "syntactic non-clausal units" (see Biber et al.) or, in the case of I wouldn't be surprised, as a clausal unit affected by ellipsis. Both cases reflect a dependence of the message on context. This reduction may be also present in the expressions in Spanish, which sometimes occur without the corresponding extraposed clausal subject, especially no me extraña: 
(18)

Ángeles es la única flor en el estercolero del Metropolitan. No me extraña. Usted siempre provoca una sensación de serenidad, de optimismo.

(Davies, Corpus del Español, entrevista, ABC)

The examples found attest the use of discourse markers in combination with these expressions, especially preceding no wonder, such as "well," "and," "so," reinforcing the dependence of the expressions on the preceding context:

From Day One, this case made front pages around the world and no wonder. The story broke at a time when Washington was lecturing other....

(COCA Corpus, 1990, SPOK, ABC 2020)

(20)

... wouldn't know the truth if it sat on you! [voice-over] Well, no wonder. Marla isn't talking.

(COCA Corpus, 1990, SPOK, ABC Primetime)

In terms of the meaning assigned to them, rather than an opinion of goodness or certainty, the expressions it is no wonder that... and I wouldn't be surprised... express an opinion concerning the likeliness of the proposition expressed in the final clause. As Hunston and Thompson point out, opinions of likelihood, unlike those of goodness, tend to be restricted to propositions and do not apply to entities, and thus they are commonly realized by clauses, rather than noun phrases (4). The same applies to the expressions under scrutiny in Spanish.

Another formal aspect worth mentioning has to do with the cohesive effect of these expressions. Where no wonder and I wouldn't be surprised occur alone, as independent units, and seen as reduced clauses, they contain a moderate amount of ellipsis, by leaving out elements which are recoverable from the preceding discourse (or even in some cases, from the situational context). In this way, these expressions function as cohesive devices, linking up with the previous discourse and adding a new element of information with a clear evaluative function. Ellipsis seems to be functioning here on two different levels. There is textual ellipsis (as opposed to situational ellipsis), where some element which can be recovered from the context of the previous discourse is omitted. Looking at the position of the omitted sequence, final ellipsis dominates against initial or medial ellipsis. The use of the discourse markers mentioned before "well," "and," "but" also reinforces the cohesive effect of the expressions. But there is also structural or linguistic ellipsis, where the dummy "it" and the form of the verb "be" in question are seen to be omitted (and may be recovered by our knowledge of the language). This of 
course only applies to no wonder, since the other expressions do not show ellipsis of structural elements such as the subject and verb. Where no wonder is used in this way, it may function as a fixed, grammaticalized unit merely introducing the new information which is placed at the end of the clause in the same sentence. Two points of information can be then identified: one expressing the likeliness of what is going to follow, with a negative tint, and a second one, adding a new proposition related to this likeliness.

There's no harm in asking. PUBLIC OPINION CHURCH OUT OF TOUCH! No wonder churches get emptier. The reason is the clergy's sheer lack of interest in....

(BNC, $\mathrm{CH} 1, \mathrm{~W} \_$newsp_tabloid, ex. 11)

Thus, this example expresses two points of information: on the one hand, the speaker announces a new proposition related to the main topic of conversation (that churches get emptier) and, on the other, it expresses his/her attitude towards this idea with respect to the likeliness of it, namely that $s /$ he is not at all surprised about it. The two points of information are sometimes reflected in the syntax by the insertion of a parenthetical unit: e.g., "I thought," or, "then," separating them.

... skin like rice-paper from the top of my head and my ears. No wonder, I thought, children draw the sun so much bigger than we see it....

(BNC, APC, W misc)

What seemed very probable after the qualitative study of the expressions became apparent after the complementary quantitative analysis. When looking through all the concordances, and after examining their extended contexts, it was found that the evaluative content of the expressions could be divided into three main categories: 1) positive, 2) negative, and 3) neutral. In effect, on most occasions the clauses under the domain of the expressions presented some kind of negative evaluative polarity towards someone or something. On some others a clear positive evaluation was made, and on some very few others there was neither a positive nor a negative evaluation: the speaker was being neutral (i.e., there was clearly no intention of criticizing or praising anything/anybody). Charts 1 and 2 show the frequencies of the three categories for the variables studied. The total number of concordances studied was the total number found in the corpora: 500 for no wonder, 403 for I wouldn't be surprised if..., 257 for no me extraña (que), 170 for no me sorprendería (que) and 154 for no me extrañaría (que). 
Chart 1: Evaluative polarity of the expressions no wonder and no me extraña (Frequency of occurrence - \%)

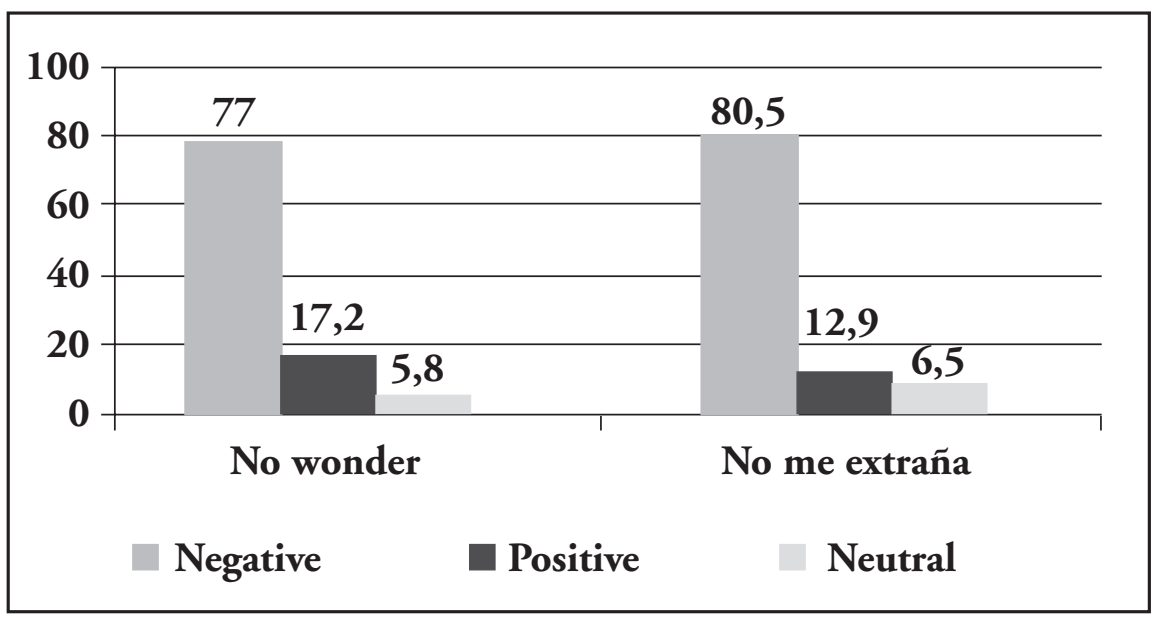

Obtained $\mathrm{x}^{2}=188.5$ for $\mathrm{p}=0.01(9.21)$ and d.f. $=2{ }^{6}$

Chart 2: Evaluative polarity of the expressions no me sorprendería..., no me extrañaría..., and $I$ wouldn't be surprised... (Frequency of occurrence - \%)

Obtained $\mathrm{x}^{2}=105.64$, for $p=0.01$ and $d . f .=4$.

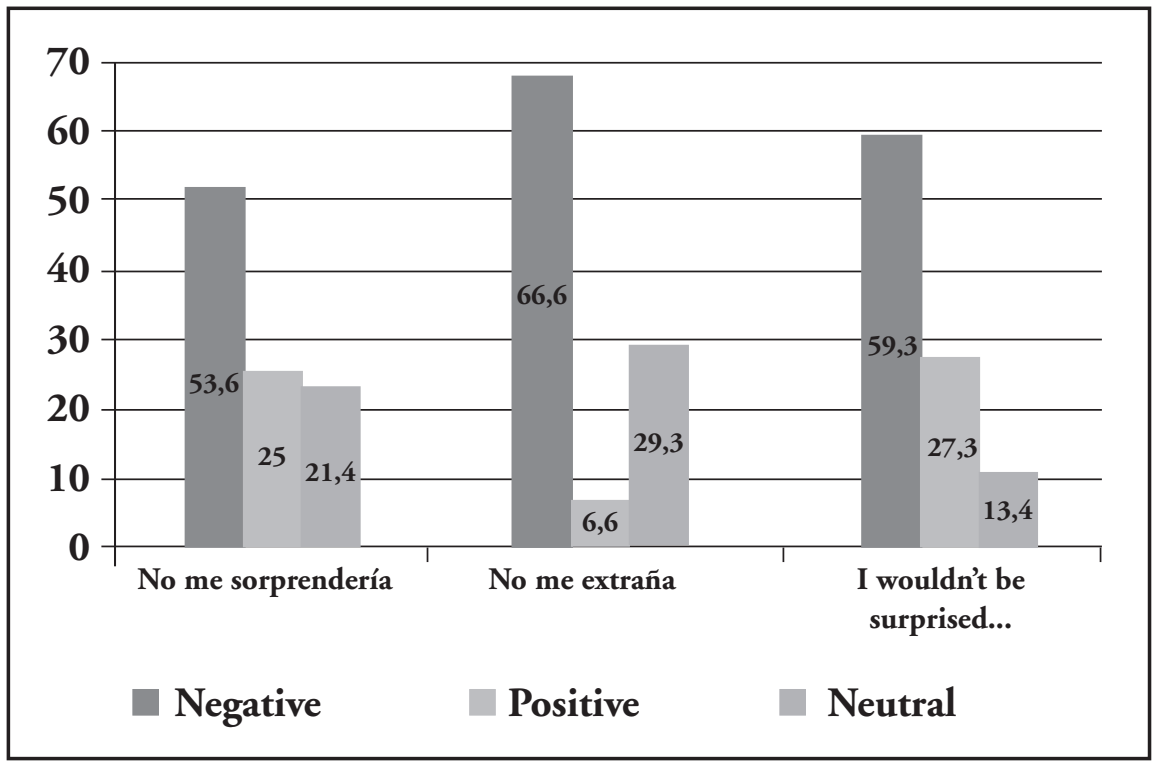


The percentages for negative polarity are notably higher for the five expressions studied. All of them are used in association with negative pragmatic meaning in the majority of cases (53\% and above). In particular, the English evaluative markers no wonder and no me extraña, present a negative polarity rate of $77 \%$ and $80.5 \%$, respectively. The $\mathrm{x}^{2}$ (chi square) values obtained for both charts $\left(\mathrm{x}^{2}=193.49\right.$ for the data in Chart 1 and $x^{2}=105.64$ for those in Chart 2) show that the frequencies obtained for negative polarity are much higher than the expected frequencies for the null hypothesis, in which case the null hypothesis (supporting there is no significant difference in the polarity with which the expressions are used) has to be rejected, and our research hypothesis (supporting there is a significant difference in favor of negative polarity) can be accepted.

An important aspect to be taken into account was the relationship between the evaluative polarity of the expressions and the genre variable. When examining the different occurrences of no wonder, etc. in the corpus one by one, it seemed apparent that, whereas there was an overwhelming majority of negative polarity in

Chart 3: Distribution of no wonder and I wouldn't be surprised... used with negative polarity according to genre (\%)

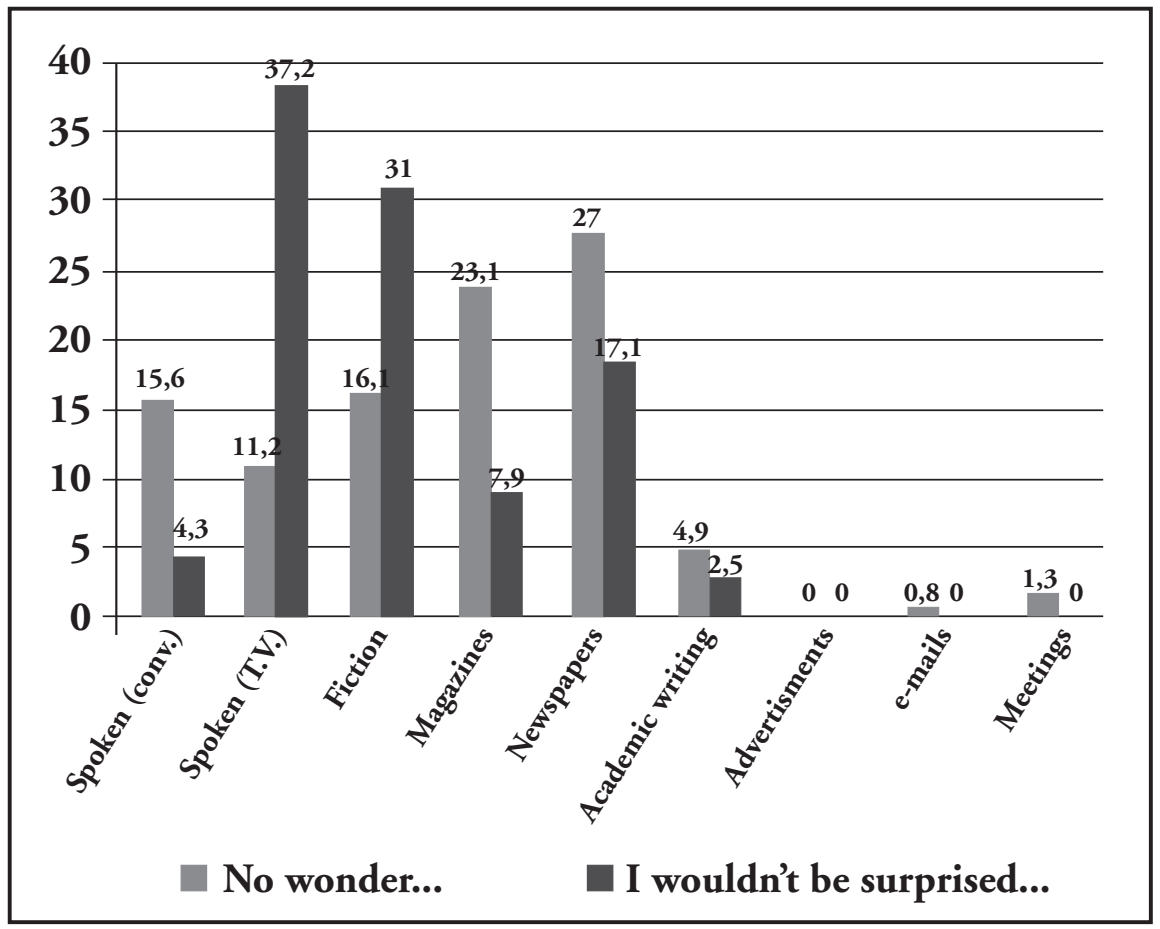


most textual types, there was, however, a certain tendency for positive polarity to appear in at least one of these types, namely, that of advertisements. Thus it was considered necessary to count the occurrences not only according to their polarity, but also according to the genre in which the three types of polarity appeared. The fact that the total number of concordances obtained for the English expressions was considerably higher than that of the Spanish ones, together with the fact that in the Spanish corpus there was a smaller variety of genres, led us to the decision of working only with the English corpus for the treatment of the genre variable, considering that the results in the Spanish corpus would be neither comparable nor significant. The genre variable percentages for the three evaluative categories-negative, positive, and neutral—in English are shown in Charts 3, 4, and 5 respectively.

Chart 4: Distribution of no wonder... and I wouldn't be surprised... used with positive polarity according to genre $(\%)$

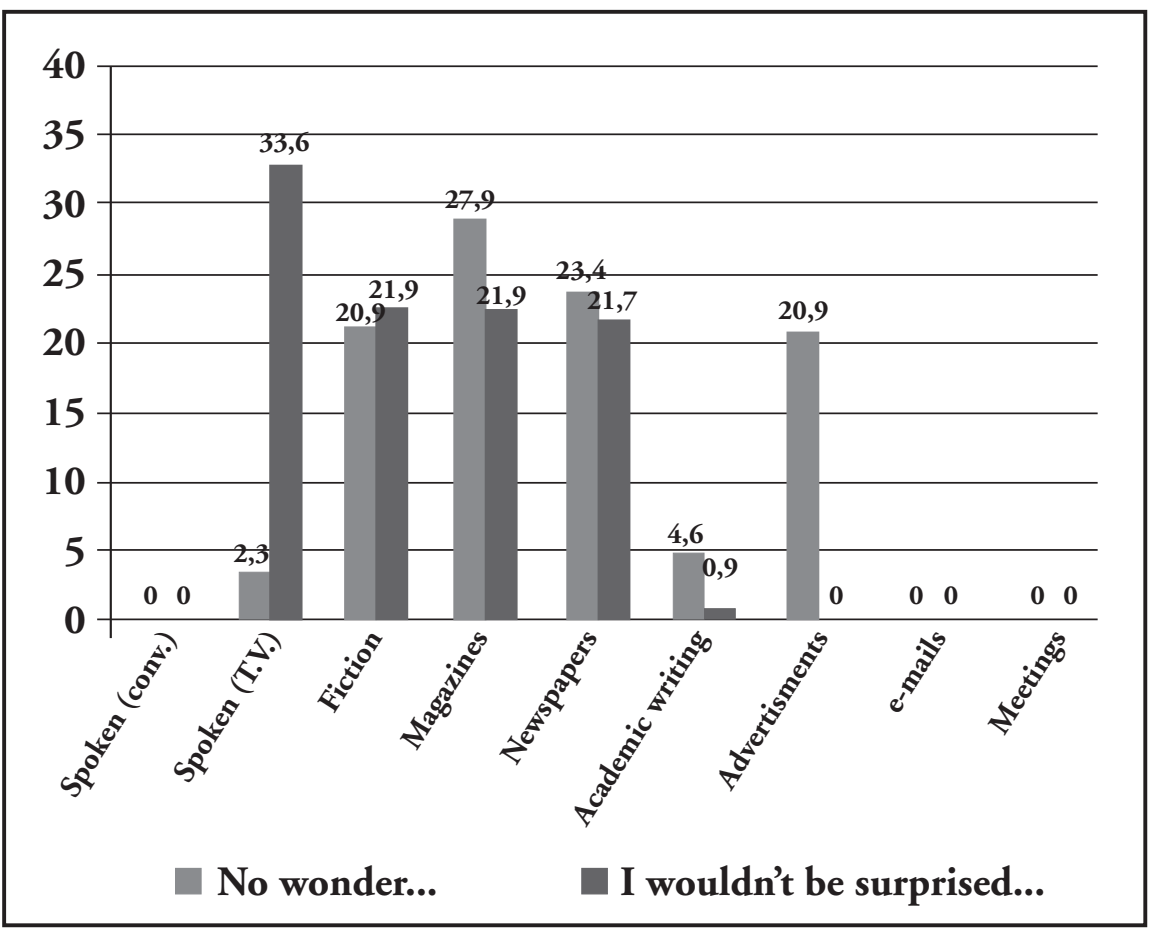

Charts 3, 4 and 5 show the frequency of occurrence of each of the evaluative options (negative, positive and neutral) in different genres with respect to the total number of concordances within each of the options. Next we present an example of how the results should be read and interpreted in these charts: 
Chart 5: Distribution of no wonder and I wouldn't be surprised... used with neutral polarity according to genre (\%)

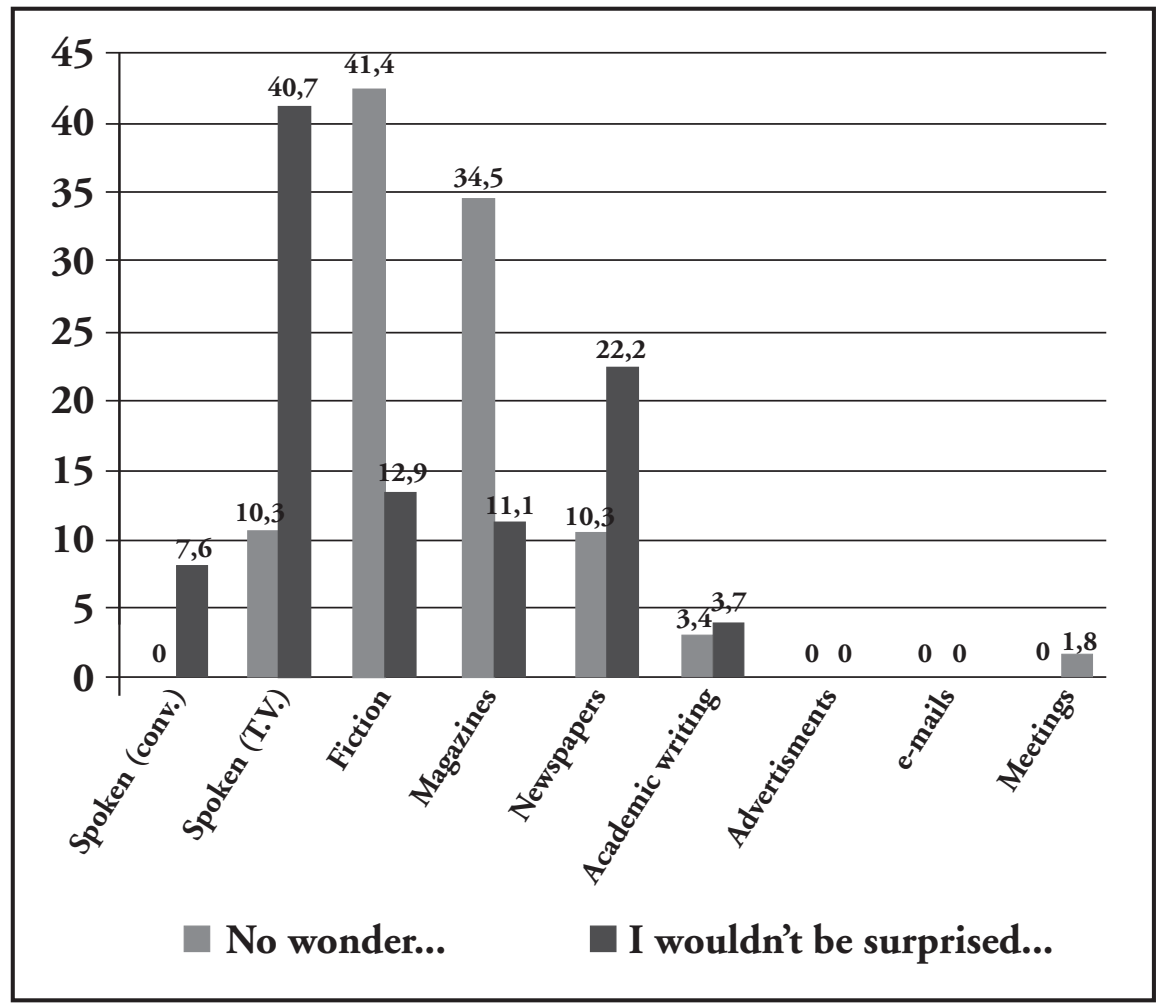

(23)

Chart 4: Of the total $n^{\circ}$ of cases $(17.2 \%$ of the total number of occurrences of the variable) in which no wonder is used with positive polarity, $20.9 \%$ (of that $17.2 \%$ ) is found within the genre of advertisements.

In order to attest whether the polarity of the two expressions (no wonder and I wouldn't be surprised iflto...) presents significant differences among the genres studied, we applied the chi square statistical test, whose results show that the differences among the various genres for the three types of polarity are significant: 
Table 2: Obtained $\mathrm{x}^{2}$ for the polarity occurrence values of no wonder.

\begin{tabular}{|l|r|r|r|r|r|r|r|}
\hline Charts 3, 4 \& 5 & & & & & & & \\
\hline NO WONDER & Negative & Expected & Positive & Expected & Neutral & Expected & Total \\
\hline Spoken Conv. & 15,60 & 5,20 & 0,00 & 5,20 & 0,00 & 5,20 & 15,60 \\
\hline Spoken T.V. & 11,20 & 7,93 & 2,30 & 7,93 & 10,30 & 7,93 & 23,80 \\
\hline Fiction & 16,10 & 26,13 & 20,90 & 26,13 & 41,40 & 26,13 & 78,40 \\
\hline Magazines & 23,10 & 28,50 & 27,90 & 28,50 & 34,50 & 28,50 & 85,50 \\
\hline Newspapers & 27,00 & 20,23 & 23,40 & 20,23 & 10,30 & 20,23 & 60,70 \\
\hline Academic writing & 4,90 & 4,33 & 4,60 & 4,33 & 3,50 & 4,33 & 13,00 \\
\hline Advertisements & 0,00 & 6,97 & 20,90 & 6,97 & 0,00 & 6,97 & 20,90 \\
\hline e-mails & 0,80 & 0,27 & 0,00 & 0,27 & 0,00 & 0,27 & 0,80 \\
\hline Meetings & 1,30 & 0,43 & 0,00 & 0,43 & 0,00 & 0,43 & 1,30 \\
\hline & 100,00 & & 100,00 & & 100,00 & & 300,00 \\
\hline Obtained X & 134,49 & & & & & & \\
\hline Degrees of freedom & 16 & & & & & & \\
\hline Significanse level (p) & 0,05 & 0,01 & & & & & \\
\hline $\mathbf{X}^{2}$ values at indicated $\mathbf{p}$ & 26,296 & 32,000 & & & & & \\
\hline
\end{tabular}

Obtained $\mathrm{x}^{2}=134.4$, for $p=0.01$ and $d . f$. $=16$.

\begin{tabular}{|c|c|c|c|c|c|c|c|}
\hline \multicolumn{8}{|l|}{ Charts 3, $4 \& 5$} \\
\hline $\begin{array}{l}\text { WOULDN'T BE } \\
\text { SURPRISED }\end{array}$ & Negative & Expected & Positive & Expected & Neutral & Expected & Total \\
\hline Spoken Conv. & 4,30 & 3,97 & 0,00 & 3,97 & 7,60 & 3,97 & 11,90 \\
\hline Spoken T.V. & 37,20 & 37,17 & 33,60 & 37,17 & 40,70 & 37,17 & 111,50 \\
\hline Fiction & 31,00 & 21,93 & 21,90 & 21,93 & 21,90 & 21,93 & 65,80 \\
\hline Magazines & 7,90 & 13,63 & 21,90 & 13,63 & 11,10 & 13,63 & 40,90 \\
\hline Newspapers & 17,10 & 20,33 & 21,70 & 20,33 & 22,20 & 20,33 & 61,00 \\
\hline Academic writing & 2,50 & 2,37 & 0,90 & 2,37 & 3,70 & 2,37 & 7,10 \\
\hline \multirow[t]{2}{*}{ Meetings } & 0,00 & 0,60 & 0,00 & 0,60 & 1,80 & 0,60 & 1,80 \\
\hline & 100,00 & & 100,00 & & 100,00 & & 300,00 \\
\hline Obtained $\mathrm{X}^{2}$ & 29,41 & & & & & & \\
\hline Degrees of freedom & 12 & & & & & & \\
\hline Significanse level (p) & 0,05 & 0,01 & & & & & \\
\hline$X^{2}$ values at indicated $p$ & 21,026 & 26,217 & & & & & \\
\hline
\end{tabular}

Obtained $\mathrm{x}^{2}=28.41$, for $p=0.01$ and $d . f .=12$.

Thus, the data in the charts and the obtained chi squared values reveal that:

- Negative polarity attached to the expressions no wonder... and I wouldn't be surprised... occurs within most of the genres (except for advertisements) included in the corpus. 
- No cases of positive or neutral polarity (with the exception of the very few cases of neutral polarity found for I wouldn't be surprised) were found when the markers were used in spoken every day conversation.

- Spoken conversation is clearly the genre where these two expressions are predominantly used with negative evaluative pragmatic meaning (almost $100 \%$ of the cases).

- Positive evaluation has no occurrence in some of the genres, and the few cases found tend to occur only within five of them: spoken TV, fiction, magazines, ads and newspapers.

- The scarce occurrences of neutral evaluation tend to appear in only four of the genres: spoken TV, fiction, magazines, and newspapers.

- The chi squared values show there is a significant deviation between the expected (null hypothesis) and the obtained results, which allows us to accept our hypothesis stating that negative evaluative pragmatic meaning is the dominant meaning with which no wonder and I wouldn't be surprised iflto... are used in general, as well as in most of the genres scrutinized in our corpus.

We believe the results of our research have shed light on the fact that the analysis of the concordanced lines of language corpora can be crucial for finding out new information regarding the evaluative function of certain words or expressions. In addition, this kind of observation allows the researcher to go beyond intuitions by revealing aspects of the evaluative function of language of which native speakers are normally not aware.

Thus we have tried to show that some individual lexical items or fixed expressions in English and Spanish can encode negative evaluative pragmatic meaning (alongside other meanings) which reflects the speaker's attitude or opinion about the content of the ongoing discourse. In effect, both the qualitative and quantitative analyses seem to indicate that the expressions under scrutiny show a rather strong tendency to be used with evaluative negative polarity at the pragmatic level, even when their inherent semantic features do not indicate any kind of polarity. This is why we conclude that the encoded negative evaluation is implicit, covert, or evoked. An objective and observable proof of the (pragmatic) evaluative negative polarity associated with these expressions is the high frequency of words containing overt negative semantic features that appear in their linguistic context.

An interesting observation and conclusion coming out of the evaluative condition of these expressions is the fact that they play a prominent role as attitudinal stance markers that also carry important evaluative cohesive devices. Stance is revealed on some occasions by using ironic language in which the 
expressions no wonder, etc. appear to be creating implicatures that accomplish off-record disapproval. Thus, the stance taken through the use of the expressions contributes to the building of a given discursive identity showing non-alignment with the ideas or people being discussed.

As had been expected, the results of the quantitative analysis have shed light on the fact that negative polarity (as part of the pragmatic meaning of these expressions) occurs much more frequently than positive or neutral polarity, and that this frequency difference is not random but significant. In spite of this common tendency in both English and Spanish, the percentages of the negative variable are higher for the English expressions than for the Spanish ones, which might mean that the pragmatic negative meaning associated with them is more deeply ingrained in the English culture than in the Spanish one. A greater body of data (especially of the Spanish use of the expressions), however, would be necessary in order to support such an assertion.

Obvious to the observer is also the fact that negative polarity is present in the great majority (all except one) of the genres analyzed, whereas the scant cases of positive and neutral polarity are found only in some of them. The only textual type where no negative evaluation was found was that of advertisements, in which, for logical reasons, the implicit evaluation of the product being advertised has to be positive, and thus it may be at least hypothesized, if not concluded, that some particular genres contain an inherently positive semantic meaning, and thus negative pragmatic meanings would be rejected or never inferred due to the mere nature of the genre. Therefore, another finding of this study is that-in the same way as the polarity of a word can shift depending on the referent to which the attribute is applied - the variable of genre definitely affects the polarity of the expressions. In other words, the evaluative polarity of certain lexical items can shift according to genre.

It has been interesting to find that there were no occurrences of positive polarity in the genre of everyday conversation, which is the prototypical and ideal genre for the study of pragmatic meaning. In fiction, as well as in media discourse, speakers/ writers would on some occasions allow themselves to detour from the more familiar, pragmatic meanings of everyday conversation in favor of non-regular or more implicitly neutral evaluations. This observation has led us to conclude that a possible reason for the absence of positive polarity in everyday conversation (in contrast with its occasional presence in the other genres examined) is that when operating in more formal registers, speakers seem to (unconsciously) feel that they can (or, on some occasions, even must) be more faithful to the strict semantic meaning of the expressions than to the colloquial pragmatic meaning normally 
associated with them in everyday conversation. Notwithstanding, the quantitative results clearly show that, even in the more formal genres, negative evaluative polarity is predominantly attached to no wonder and I wouldn't be surprised iftto..., while positive and neutral polarity are rare.

As a more general conclusion, we deem it necessary to point out that the notion of evaluative function is crucial for the description of an important number of words or expressions, and that therefore, as Channel argues for all cases (54), information about this aspect should be included in all descriptions of the lexical meaning of no wonder, etc., including those of dictionaries.

\section{Notes}

${ }^{1}$ The research presented in this article has been funded by the Spanish Ministry of Science and Innovation (FFI2009-07308 /FILO).

${ }^{2}$ We did not have enough data in the Spanish corpora to obtain reliable and significant quantitative results related to the variable of genre.

${ }^{3}$ See, for instance, Gazdar's formulation (2).

${ }^{4}$ Fotion, for example, states the difference as follows: "Pragmatics is the study of language which focuses attention on the users and the context of language use rather than on reference, truth, or grammar" (709).

${ }^{5}$ An exception is where the subject of the extraposed clause (1st-person singular, "yo") has the same referent as the experiencer of the verbal process of the main clause ("a mí/me"), in which case the extraposed clause must be an infinitive clause (e.g. "No me extrañaría saber que ha aprobado; No me sorprende haber suspendido").

${ }^{6}$ Where $p=$ significance level, and $d . f$. $=$ degrees of freedom.

${ }^{7}$ Channel, for instance, explains how the word "fat" can encode a very negative evaluation when the referent is a person, but a very positive one if the referent is an animal: e.g., "cute fat piglets" (43).

\section{Works Cited}

Alba-Juez, Laura. The Functions and Strategies of Ironic Discourse: An Analysis. Madrid: Servicio de Publicaciones de la Universidad Complutense, 2001. CD.

. "Irony and the Other Off Record Strategies within Politeness Theory." Miscelanea: A Journal of English and American Studies 16 (1995): 13-23.

. "Irony and Politeness." Revista Española de Lingüistica Aplicada 10 (1995): 9-16.

. "On the Impoliteness of Some Politeness Strategies: A Study and Comparison of the Use of Some Pragmatic Markers of Impoliteness in British English and American English, Peninsular Spanish and Argentine Spanish." Studies in Intercultural, Cognitive and Social 
Pragmatics. Ed. Pilar Garcés-Conejos, Manuel Padilla Cruz, Reyes Gómez Morón and Lucía Fernández Amaya. Newcastle upon Tyne, UK: Cambridge Scholars Publishing, 2007. 37-56.

. "Verbal Irony and the Maxims of Grice's Cooperative Principle." Revista Alicantina de Estudios Ingleses 8 (1995): 25-30.

Attardo, Salvatore. "On the pragmatic nature of irony and its rhetorical aspects." Pragmatics in 2000. Ed. Eniko Nemeth. Antwerp: IPrA, 2001. 52-66.

Barbe, Katherina. Irony in Context. Amsterdam: Benjamins, 1995.

Biber, Douglas, Stig Johansson, Geoffrey Leech, Susan Conrad, and Edward Finegan. Longman Grammar of Spoken and Written English. London: Longman, 1999.

Brown, Penelope and Stephen Levinson. Politeness: Some Universals in Language Use. Cambridge: Cambridge University Press, 1987.

Channel, Joanna. "Corpus-based analysis of evaluative lexis." Evaluation in Text. Authorial Stance and the Construction of Discourse. Ed. Susan Hunston and Geoff Thompson. Oxford: Oxford University Press, 1999. 38-55.

Conrad, Susan and Douglas Biber. "Adverbial marking of stance in speech and writing." Evaluation in Text. Authorial Stance and the Construction of Discourse. Ed. Susan Hunston and Geoff Thompson. Oxford: Oxford University Press, 1999. 56-73.

CREA: Corpus de referencia del español actual. Banco de datos. Real Academia Español. http:// www.rae.es.

Davies, Mark. VIEW (Variation in English Words and Phrases). Online concordances from the $B N C$ and COCA corpora: http://view.byu.edu/.

Fetzer, Anita. "The expression of non-alignment in British and German political interviews: Preferred and dispreferred variants." Evaluation in Text Types. Special issue of Functions of Language 15:1 (2008): 35-65.

Fotion, Nick. "Pragmatics." The Oxford Companion to Philosophy. Ed. T. Honderich. Oxford: Oxford University Press, 1995.

Gazdar, Gerald. Pragmatics: Implicature, Presupposition and Logical Form. New York: Academic Press, 1979.

Hunston, Susan and Geoff Thompson, eds. Evaluation in Text. Authorial Stance and the Construction of Discourse. Oxford: Oxford University Press, 1999.

Kaul de Marlangeon, Silvia. "Uso estratégico de la ironía." Anales. Instituto de Lingüística 18, 19, 20, y 21 (1999): 141-150.

Louw, B. "Irony in the text or insincerity in the writer? The diagnostic potential of semantic prosodies." Text and Technology: In Honour of John Sinclair. Ed. M. Baker, G. Francis and E. Tognini-Bognelli. Amsterdam: John Benjamins, 1993. 157-176.

Martin, J.R. "Appraisal Systems in English." Evaluation in Text. Authorial Stance and the Construction of Discourse. Ed. Susan Hunston and Geoff Thompson. Oxford: Oxford University Press, 1999. 142-175. 
Martin, J.R. and Peter R.R. White. The Language of Evaluation. Appraisal in English. New York: Palgrave Macmillan, 2005.

Sinclair, John M. Corpus Concordance Collocation. Oxford: Oxford University Press, 1991.

Torres Sánchez, María Ángeles. "La relevancia.” Dime cómo ironizas y te diré quién eres. Una aproximación pragmática a la ironía. Ed. L. Ruiz Gurillo, L. and X.A. Padilla García. Frankfurt: Peter Lang, 2009. 65-88. 